\title{
Enhancement of Voltage Stability Margin Using FACTS Controllers
}

\author{
H. B. Nagesh and P. S. Puttaswamy
}

\begin{abstract}
This paper presents a methodology for selection of location of static VAR compensator based on static voltage stability analysis of a power system. The analysis presented here uses the L-index of load buses. This includes voltage stability information of a normal power flow in the range of 0 to 1(no load to voltage collapse). An approach has been developed to select a suitable size and location of static VAR compensator as required in an IEEE-14 bus system. The STATCOM and SVC are used in the continuation power flow process for static voltage stability analysis to enhance stability margin.
\end{abstract}

Index Terms - L-index, loading margin, STATCOM, SVC.

\section{INTRODUCTION}

The increase in loading of existing power transmission system results in the problems of voltage stability and voltage collapse. This has become a major concern in power system planning and operation. In recent years environmental concerns and deregulation of power utilities have delayed the construction of new transmission facilities. Hence with the existing transmission system itself better utilization has to be obtained. Recently developed power electronic based controllers have been used to meet this requirement. These controllers make the transmission system more flexible in terms of controlling the active and reactive power transfer and as well as the voltage profile of a power system.

The power electronic devices are used as controllers. The FACTS controller stands for Flexible AC Transmission System. The potential benefits offered by these controllers are reduced cost of operation and increased reliability of a power system. There are five types of FACTS devices such as static VAR compensator (SVC), static synchronous compensator (STATCOM), and thyristor controlled series capacitor (TCSC), static synchronous series compensator (SSSC) and unified power flow controller (UPFC). Each of them has its own features and limitations.

From the utility point of view, they are useful if they can achieve desired voltage stability criterion with the help of the most beneficial FACTS devices. Many works in the literatures [1][2][3], consider only the $\mathrm{AC}$ equations for voltage stability studies. This may lead to non-practical solutions in the DC parts of the FACTS devices. In voltage stability assessment of the system with shunt compensation

Manuscript received October 24, 2012; revised November 25, 2012.

H. B. Nagesh is with the Department of Electrical and Electronics, Bangalore Institute of Technology, V. V. Puram, Bangalore-560004, Karnataka, India. (e-mail: hulivana_nagesh@rediffmail.com)

P. S. Puttaswamy is with the Department of Electrical and Electronics, PES College of Engineering, Mandya-571401, Karnataka, India. (e-mail: psputtaswamy_ee@yahoo.com) devices like SVC and STATCOM has been compared with the IEEE 14-bus system. For this purpose appropriate representation of equations in the DC parts of SVC and STATCOM is incorporated in the continuation power flow (CPF) process in static voltage stability studies.

\section{Static Voltage StabiLITy}

Voltage instability is mainly occurs due to reactive power imbalance. The loadbility of a bus in the power system depends on the reactive power support that the bus can receive from the system. When the system approaches the maximum loading point or to the point of voltage collapse both real and reactive power losses increases rapidly. Therefore the reactive power supports has to be local and must be adequate to satisfy the requirement.

There are two types of voltage stability based on the time frame simulation they are static voltage stability and dynamic voltage stability. Static voltage stability analysis involves the solution only based on algebraic equation and hence it is computationally less extensive than that of time required by dynamic stability analysis. Static voltage stability is ideal for bulk studies in which voltage stability limit for many pre-contingency and post-contingency cases must be evaluated. In static voltage stability, slowly developing changes in the power system eventually leads to a reduction of reactive power and voltage declining. This phenomenon can be seen from the plot of the power transferred versus the voltage at receiving end characteristics. The plots are popularly referred to as $\mathrm{P}-\mathrm{V}$ curves or "Nose" curves. As the power transfer increases the voltage at the receiving end decreases. This eventually leads to the critical (nose) point i.e. the point at which the system reactive power is low in power supply. Any further increase in active power transfer will always lead to rapid decrease in voltage magnitude. Before reaching the critical point, the large voltage drop takes place due to more reactive power losses. Now only way to save the system from voltage collapse is by reducing the reactive power load or add additional reactive power prior to reaching the point of voltage collapse.

In practice, placing adequate reactive power support at the "weakest bus" enhances static-voltage stability margins. The weakest bus is defined as the bus which is near to experience a voltage collapse. Equivalently, the weakest bus is one that has a large ratio of differential change in voltage to differential change in load $\left(\mathrm{dv}^{\mathrm{d}} / \mathrm{dp}_{\text {total }}\right)$.Changes in voltage at each bus for a given change in system load has been evaluated from the L-index of load buses[3].

Hence the reactive power support required can be provided through FACTS controllers. Each FACTS device has 
different characteristics; some of them may be problematic as far as the static voltage stability is concerned. Therefore, it is important to study their behaviors in order to use them effectively and more efficiently.

\section{MODEL OF FACTS CONTROLLERS}

The model which has chosen for voltage collapse studies includes correct representation of dc equation in both SVC and STATCOM [4]. The model includes a set of differential and algebraic equations are of the form:

$$
\begin{aligned}
& X_{\mathrm{C}}=f_{\mathrm{C}}\left(x_{\mathrm{C}}, v, \theta, u\right) \\
& P=g_{\mathrm{P}}\left(x_{\mathrm{C}}, v, \theta\right) \\
& Q=g_{\mathrm{P}}\left(x_{\mathrm{C}}, v, \theta\right)
\end{aligned}
$$

where $x_{\mathrm{C}}$ represents the control system variables and the algebraic variables $v$ and $\theta$ denote the voltage magnitudes and phases at the buses to which the FACTS devices are connected. The variable $u$ represents the input control parameters, such as reference voltage or reference power flows. Description and terminal characteristics of these FACTS controllers are explained below.

\section{A. SVC}

The SVC is taken to be a continuous, variable -shunt susceptance, which is adjusted in order to achieve a specified voltage magnitude, while satisfying constraints. There are two types of SVC models, and they are SVC total susceptance model and SVC firing angle model. The SVC total susceptance model [5] is used in this paper. A changing susceptance $B_{\mathrm{SvC}}$ represents the fundamental frequency equivalent susceptance of all shunt modules making up the SVC. This model is an improved version of currently available SVC model.

Advances in power electronics technology together with sophisticated control methods made it possible to the development of fast SVC's in the early 1970's. The SVC's consists of a group of shunt-connected capacitors and reactor banks with fast control action achieved by means of thyristor switching. From the operational point of view, the SVC can be seen as a variable shunt reactance that adjusts automatically in response to system operating conditions. Depending on the nature of equivalent SVC's reactance i.e., may be either capacitive or inductive, and then SVC draws either capacitive or inductive current from the network. Suitable control of their equivalent reactance allows voltage magnitude regulation at the SVC point of connection. SVCs achieve their main operating characteristics at the expense of generating harmonic currents. The filters are employed with this kind of devices to eliminate them.

SVC's normally include a combination of mechanically controlled and thyristor controlled shunt capacitors and reactors. The most popular configuration for continuously controlled SVC's is the combination of either fix capacitor and thyristor controlled reactor or thyristor switched capacitor and thyristor reactor [6], [7]. Fig. 1 and Fig.2 show the schematic diagram and terminal characteristics of SVC respectively. This representation is used to derive an SVC model.

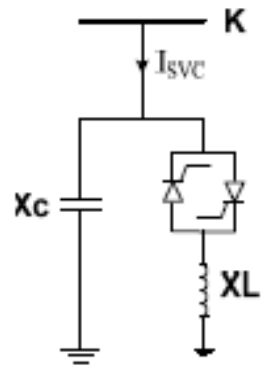

Fig. 1. Basic structure of SVC

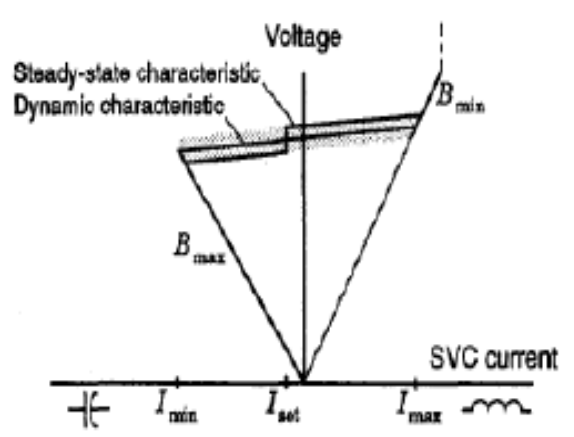

Fig. 2. Terminal characteristic of SVC

\section{B. STATCOM}

STATCOM is the voltage - sources inverter (VSI), which converts a DC input voltage into AC output voltage in order to compensate the active and reactive power needed by the systems. Fig. 3 and Fig. 4 respectively show the schematic diagram and terminal characteristic of STATCOM. From Fig. 3, STATCOM is a shunt -connected device, which controls the voltage at the connected bus to the reference value by adjusting voltage and angle of internal voltage source. From Fig. 4, STATCOM exhibits constant current characteristics when the voltage is low/high or under/over the limit. This allows STATCOM to deliver constant reactive power at the limits compared to SVC.

It is well known fact that FACTS devices can be used to provide reactive power compensation. Table I gives an idea about the cost of various reactive power sources including all FACTS devices [8]. Although FACTS devices are expensive, they can provide smooth and fast response to make secured power system during normal and steady state operations. Shunt capacitors, on the other hand provides coarse response and cannot control voltage at the other connected lines [9].Although there are many types of the FACTS devices each of them have their own characteristics. Thus, it would be useful know what type among SVC and STATCOM capable of providing the most benefit in terms of voltage stability margin.

\section{TEST System AND ANALYTICAL TOOLS}

A Single line diagram of the IEEE 14 bus test system is depicted in Fig.5. It consists of the five synchronous machines including three synchronous compensators which are used only for reactive power support. 


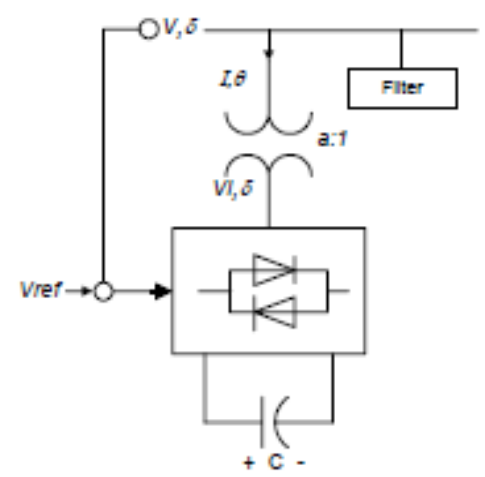

Fig. 3. Basic structure of STATCOM

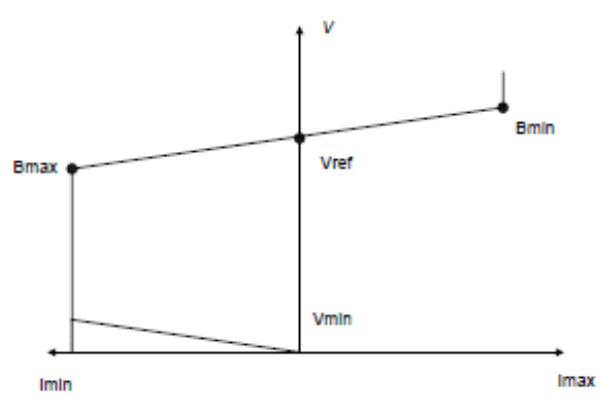

Fig. 4. Terminal characteristic of STATCOM

TABLE I: COST COMPARISON OF VARIOUS CONTROLLERS

\begin{tabular}{ll}
\hline Capacitor and FACTS & Cost(US\$) \\
\hline Shunt capacitor & $8 / \mathrm{kvar}$ \\
Series capacitor & $20 / \mathrm{kvar}$ \\
SVC & $40 / \mathrm{kvar}$ Controlled portions \\
TCSC & $40 / \mathrm{kvar}$ Controlled portions \\
STATCOM & $50 / \mathrm{kvar}$ \\
UPFC series portions & $50 / \mathrm{kvar}$ Through power \\
UPFC shunt portions & $50 / \mathrm{kvar}$ Controlled portions \\
\hline
\end{tabular}

There are twenty branches and fourteen buses with eleven loads totaling of 259MW and 81.4 MVAr.

All the results presented in the paper are produced with the help of the Power System Analytical Tool, PSAT. PSAT is a research tool that has been designed to calculate the maximum loading margin of a power system associated with a saddle node and limit-induced bifurcation for a given load and generation direction. The program has detailed static models of various power system elements like generators, loads, HVDC links, and various FACTS controllers. Particularly SVC and STATCOM controllers in phase and PWM control schemes, representing control limits with accuracy for all models.

In this study, in order to obtain P-V curves and hence the loading margins of the system for different cases, all loads were represented as constant PQ and increased simultaneously according to equation (2) i.e. maintaining constant power factor.

$$
\begin{aligned}
& \mathrm{P}_{\mathrm{L}}=\mathrm{P}_{0}(1+\lambda) \\
& \mathrm{Q}_{\mathrm{L}}=\mathrm{Q}_{0}(1+\lambda)
\end{aligned}
$$

where $P_{0}$ and $Q_{0}$ correspond to the base loading conditions and $\lambda$ is the loading factor (LF).

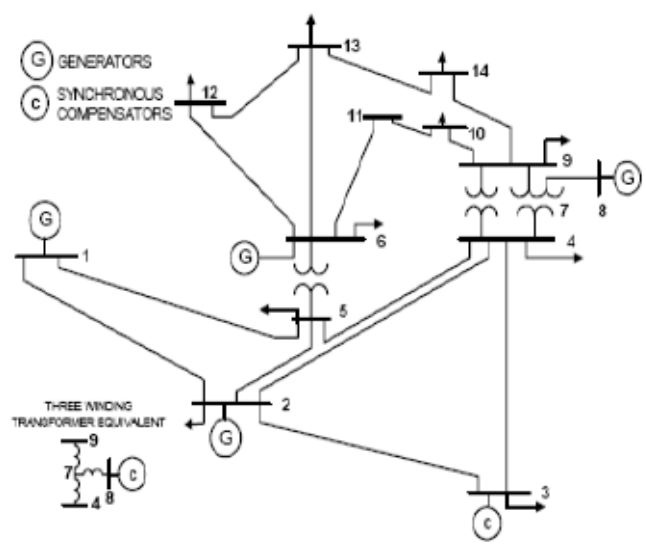

Fig. 5. Single line diagram of IEEE14 test system.

\section{RESULT AND DisCUSSION}

\section{A. Identification of Weak Bus by L-Index}

The best location for reactive power compensation for the improvement of static voltage stability margin is considering identified by the "weakest bus" of the system. The weakest bus of the system can be identified using the L- indices for a given load condition, and is computed for all load buses. The estimated value of L-index is varying between 0 and 1. Based on this value, we can able to identify the voltage stability margin. If the estimated value approaches 1 refers voltage collapse where as the estimated value approaches 0 refers the under no-load condition. Otherwise the system is under normal operating condition. The higher values for L-indices are indicative of most critical buses and thus maximum of L-indices $\left(\mathrm{L}_{\max }\right)$ is an indicator of proximity in the system to represent voltage collapse. Table II shows the first four weakest buses and bus 14 is considered as the best location to provide reactive power support. Based on the studies carried out with the developed model the following are the results obtained based on L-index method.

TABLE II: L-INDEX OF THE FIRST FOUR WEAKEST BUSES

\begin{tabular}{lllll}
\hline Load bus & 8 & 9 & 10 & 14 \\
\hline L-index & 0.0376 & 0.0664 & 0.0633 & 0.0767 \\
\hline
\end{tabular}

\section{B. Rated Capacities of SVC and STATCOM}

Once the weakest bus is identified the next objective is to provide the required compensation. In order to get approximate reactive power [9] support needed at the weakest bus for the corresponding load margin, for a given load and generation direction, a synchronous compensator without limit on reactive power has been used at the weakest bus. The amount of reactive power generated at the maximum loading point from the synchronous compensator was found to be $150 \mathrm{MVAr}$.

Another method of determining the capacities is to find the relationship between the maximum loading factor (LF) and the corresponding capacities that the devices can deliver without causing voltage collapse. The loading factor is the factor by which real and reactive power loads are increased to determine the maximum loading point, according to equation (2). 


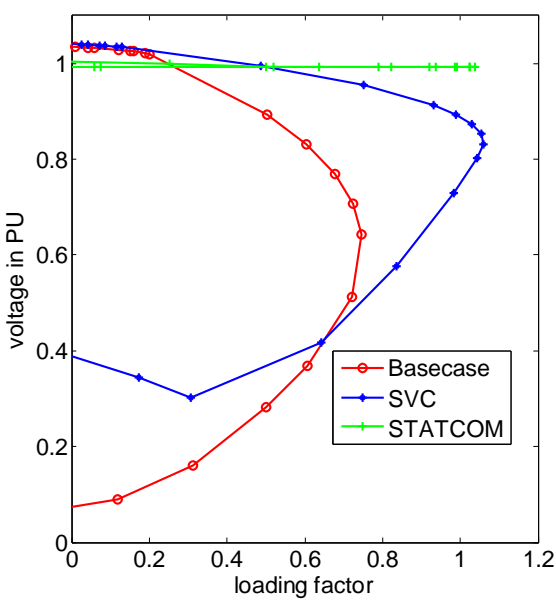

Fig . 6. PV curves of base case and system with SVC and STATCOM at bus 14.

\begin{tabular}{llll}
\multicolumn{4}{l}{ TABLE III: LOADING MARGIN WITH VARIOUS FACTS DEVICES } \\
\hline & Base Case & SVC & STATCOM \\
\hline LM[p.u.] & 0.7808 & 1.0276 & 1.0735 \\
\hline
\end{tabular}

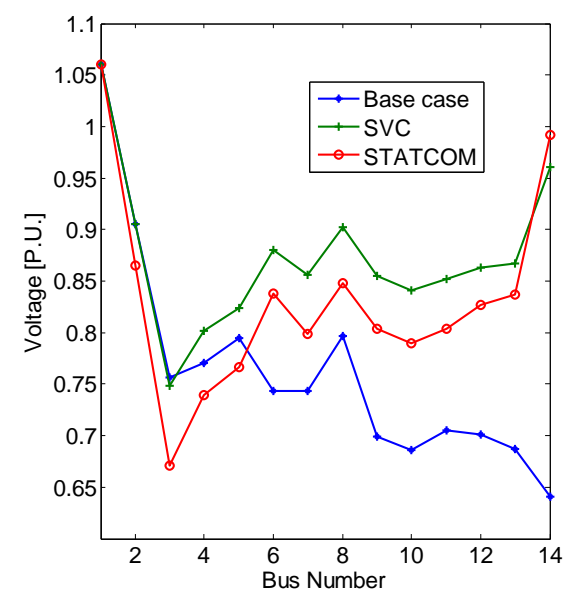

Fig. 7. Voltage profile of system for base case, with SVC and with STATCOM

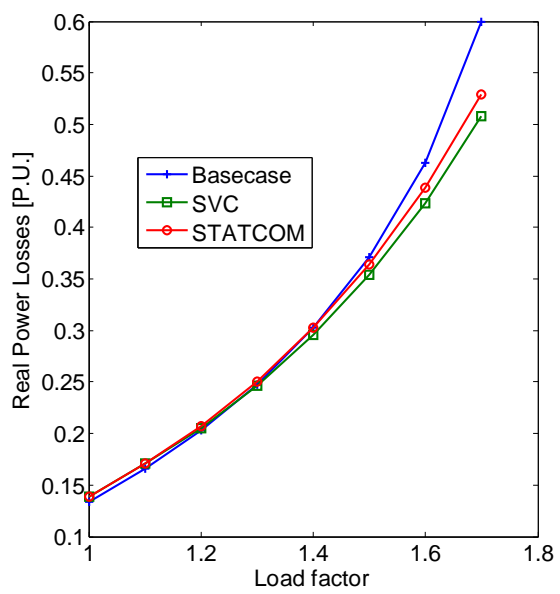

Fig. 8. Active power losses of the system for base case, with SVC and with STATCOM

\section{Comparison of SVC and STATCOM}

PV curves of base case and system with SVC and STATCOM are illustrated in Fig. 6. It indicates that with the application of SVC and STATCOM, voltage profile in bus 14 has improved significantly. Initially the system experiences light load, then the voltage profile of this bus with SVC and STATCOM are the same. During this condition SVC and STATCOM operate in the linear region of their V-I characteristics. When the load of the system is increased, the effect of STATCOM has been studied which shows the improvement in the voltage margin than that of SVC. When the maximum limit is reached, the SVC behaves exactly like a fixed shunt capacitor. The values of LMs with and without FACTS devices are compared in Table III.

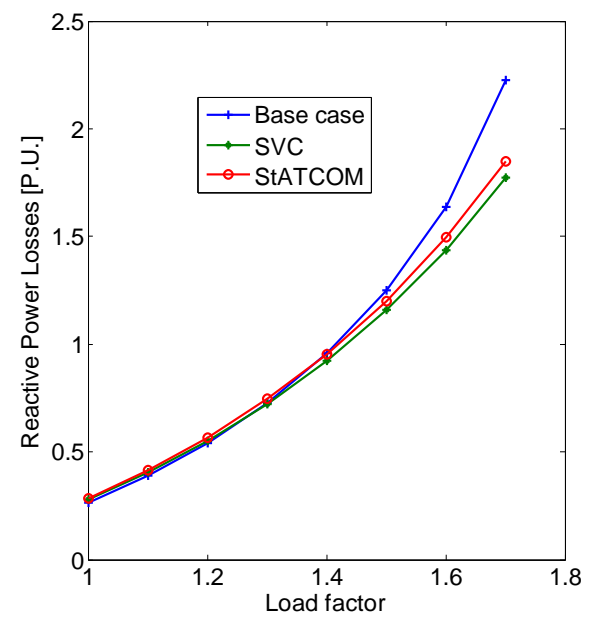

Fig. 9. Reactive power losses of the system for base case, with SVC and with STATCOM

Voltage profile at the point of collapse of base case and system with FACTS devices are shown in Fig.7. Fig.7 reveals that STATCOM provides a better voltage profile compared to base case and SVC .This is due to the fact that the STATCOM is installed at the weakest bus. Reactive power support at the weakest bus provides better voltage profiles throughout the system.

Real and reactive power losses of the system at various loading factors are shown in Fig. 8 and Fig.9 respectively. At the higher loading factor both real and reactive power losses increase very rapidly. The increase of losses near the collapse point is lowest in the case of SVC as compared to base case and in the case of STATCOM.

\section{CONCLUSION}

A comparison study of SVC and STATCOM in static voltage stability margin enhancement is presented. Both SVC and STATCOM capable of increasing static voltage stability margin as well as power transfer capability. When the load margin (LM) is considered then SVC is the better choice, where as when the voltage profile is considered then better choice is STATCOM.

\section{REFERENCES}

[1] N. Mithulanathan, C. A. Canizares, and J. Reeve, "Comparison of PSS SVC and STATCOM Controllers for Damping Power System Oscillations," IEEE Trans.Power System, pp. 786-792, 2003.

[2] A. S. Yome and N. Mithulanathan, "Static Voltage Stability Margin Enhancements using STATCOM, TCSC, and SSSC," IEEE/PES, Transmission and Distribution, Conference and Exhibition: Asia and Pacific, Dalian, China, 2005. 
[3] D. Thukaram and A. Lomi, "Selection of Static VAR Compensator Location and Size for System Voltage Stability Improvements," Electrical Power System Research, vol. 54, pp. 139-150, 2000.

[4] C. A. Canizares, "Power flow and transient stability models of FACTS controllers for the voltage and angle stability studies," in Proc. of the 2000 IEEE-PES winter meeting, Singapore, January 2000.

[5] K. R. Padiyar, FACTS Controllers in Power Transmission and Distribution, New Age International Publishers, vol. 4.

[6] T. J. E Miller, Reactive Power Control in Electric Systems, Wiley Interscience, 1982, vol. 4, pp. 204-214.

[7] H. A. Perez, E. Ache, and C. R. F. Esquivel, "Advanced SVC Models for the Newton-Raphson load flow and Newton optimal power flow studies," IEEE Transactions on the power systems, vol. 15, no. 1, pp. 129-136, February 2000.

[8] Cigre 95 TP108, FACTS overview, IEEE Power Engineering Society, 1995.

[9] A. S. Yome and N. Mithulanathan, "Comparison of Shunt Capacitor, SVC and STATCOM in Static Voltage Stability Margin Enhancement," International Journal of Electrical Engineering Education, UMSIT, vol. 41, no. 3, July 2004.

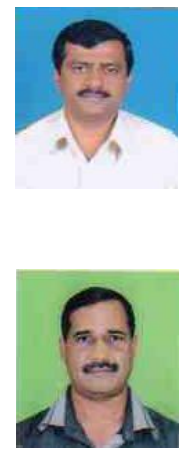

H. B. Nagesh received the BE degree in Electrical and Electronics Engineering from University of Mysore Mysore, India in 1991, Post Graduation in Power Systems from University of Mysore, Mysore, India in 1994.His areas of interests are power systems operation and control, voltage stability and applications of FACTS controllers in transmission systems.

P. S. Puttaswamy received the BE degree in Electrical Power from University of Mysore, Mysore, India in 1983 post graduation in power apparatus and electric drives in Indian Institute of Technology, Roorkee, India in 1989.The PhD degree in power apparatus and electric drives at Indian Institute of Technology, Roorkee, India in 2000.The area of research interests are power converters, Image processing, electric drives and controls, and soft computing techniques. He has several research papers published at national and international level conferences and journals. 